Rapid Communications

\title{
A Disposable, Screen-Printed Electrode for the Amperometric Determination of Azide Based on the Immobilization with Catalase or Tyrosinase
}

\author{
Yue CuI, ${ }^{\dagger}$ John P. BARFord, and Reinhard RenNEBERG \\ Department of Chemical Engineering and Department of Chemistry, Hong Kong University of Science \\ and Technology, Clear Water Bay, Kowloon, Hong Kong
}

\begin{abstract}
A disposable, screen-printed electrode based on the immobilization of catalase or tyrosinase was developed to construct biosensors for the amperometric determination of azide. The determination principles for azide by these two methods are based on inhibiting the enzymatic consumption of an electrode-detectable substance (hydrogen peroxide or catechol) on an enzyme-immobilized electrode. Both of these methods show a sensitive detection range and a short measuring time.
\end{abstract}

(Received July 21, 2006; Accepted September 15, 2006)

Sodium azide is a rapidly acting toxic chemical that exists as an odorless white solid. It prevents cells from using oxygen, and is thus very harmful to organs, especially the heart and the brain. In addition, sodium azide is used daily in the air-bags of vehicles with large tonnage, in hospitals and laboratories as a chemical preservative, in agriculture for pest control, and detonators and other explosives. Moreover, sodium azide is the starting materials of heavy sodium azide, pure sodium metal, hydrazoic acid, and a variety of medicines. ${ }^{1-4}$

Due to its importance, various methods have been developed for the determination of azide concentration, including ion chromatography, ${ }^{5,6}$ gas chromatography, ${ }^{7}$ high-performance liquid chromatography, ${ }^{8}$ and the combination of diffusion extraction and spectrophotometry. ${ }^{9}$ However, these methods either require expensive equipment or need to be performed by skilled personnel. With increasing importance of amperometric biosensors due to the advantages of being highly sensitive, rapid, economical and easy-to-handle for measurements, several types of biosensors have been constructed for the determination of azide based on the inhibition of enzymatic activity, including a laccase or tyrosinase immobilized mediated carbon electrode, ${ }^{10,11}$ and a catalase immobilized Clark-type oxygen electrode. ${ }^{12}$ In this paper, we report on new methods to construct biosensors for the amperometric determination of azide by using a disposable, screen-printed electrode immobilized with catalase or tyrosinase, as shown in Fig. 1.

The first method for azide determination is based on inhibiting the enzymatic consumption of $\mathrm{H}_{2} \mathrm{O}_{2}$ on a catalase-immobilized screen-printed electrode by azide, as shown in Fig. 1(A). $\mathrm{H}_{2} \mathrm{O}_{2}$ can result in a high current due to its oxidation at the working electrode; however, the immobilized catalase on the electrode initiates the decomposition of $\mathrm{H}_{2} \mathrm{O}_{2}$ into $\mathrm{H}_{2} \mathrm{O}$ and $\mathrm{O}_{2}$, which consumes $\mathrm{H}_{2} \mathrm{O}_{2}$ at the electrode surface considerably, and therefore the current response to $\mathrm{H}_{2} \mathrm{O}_{2}$ is not apparent. The presence of azide inhibits the enzymatic activity of catalase, and thus the consumption of $\mathrm{H}_{2} \mathrm{O}_{2}$ by catalase on the electrode decreases, followed by a significant increase of the current signal, and the current difference after the injection of azide is

$\doteqdot$ To whom correspondence should be addressed.

E-mail: kecuiyue@ust.hk proportional to the concentration of azide.

The second method for azide determination is based on inhibiting the enzymatic consumption of catechol on a tyrosinase-immobilized screen-printed electrode by azide, as shown in Fig. 1(B). Catechol can result in a high current due to its oxidation at the working electrode; however, the immobilized tyrosinase on the electrode converts it into benzoquinone in the presence of oxygen, which consumes catechol at the electrode surface significantly, and therefore the current response to catechol using the tyrosinase-immobilized electrode is much smaller than that using a bare electrode. The presence of azide inhibits the enzymatic activity of tyrosinase, and thus the consumption of catechol by tyrosinase on the electrode decreases, followed by a significant increase of the current signal; the current difference after the injection of azide is proportional to the concentration of azide.

\section{Experimental}

Apparatus

A potentiostat EP30 (Biometria, Germany) and a computer installed with the software FIABOLO were used. The screenprinted electrode (BioSensorTrend, Germany) with a 2electrode configuration was composed of a platinum (Pt)

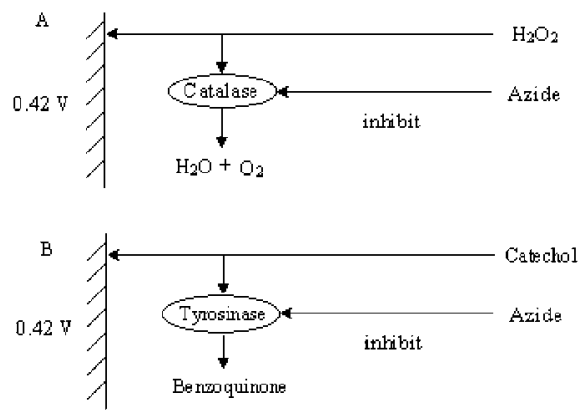

Fig. 1 Schematic illustration for azide determination with (A) the catalase-immobilized screen-printed electrode and (B) the tyrosinaseimmobilized screen-printed electrode. 
working electrode (diameter: $1 \mathrm{~mm}$ ) and an $\mathrm{Ag} / \mathrm{AgCl}$ reference/counter electrode. A measuring cell (volume: $1 \mathrm{ml}$ ), connected to a syringe and installed with two connectors (cathode and anode) and an electrode-fitting site, was constructed for experiments.

\section{Chemicals}

Catalase (EC 1.11.1.6, from Bovine Liver), tyrosinase (1.14.18.1, from Mushroom), and catechol were from SigmaAldrich (USA). Potassium dihydrogen phosphate $\left(\mathrm{KH}_{2} \mathrm{PO}_{4}\right)$, dipotassium hydrogen phosphate $\left(\mathrm{K}_{2} \mathrm{HPO}_{4}\right)$, sodium azide, and hydrogen peroxide $\left(\mathrm{H}_{2} \mathrm{O}_{2}\right)$ were from Riedel-deHäen (Germany).

\section{Enzyme-electrode preparations}

A screen-printed electrode was covered by a $0.5 \mu \mathrm{l}$ mixture containing $75 \mathrm{U}$ catalase and $1 \%$ glutaraldehyde, or $75 \mathrm{U}$ tyrosinase and $1 \%$ glutaraldehyde, followed by drying and storing at $4^{\circ} \mathrm{C}$ overnight. The enzyme-electrode was then screwed into the measuring cell, which was filled with a buffer solution, and rehydrated for around $1 \mathrm{~h}$ at room temperature $\left(22^{\circ} \mathrm{C}\right)$ to allow the enzyme matrix to swell before use.

\section{Amperometric measurement}

Experiments were performed at room temperature by applying a specific potential for this type of screen-printed electrode at $0.42 \mathrm{~V}$ (the recommended potential by BioSensorTrend) and magnetically stirring the solution at $300 \mathrm{rpm}$ to obtain a uniform distribution of azide. The measurements were carried out in a $50 \mathrm{mM}$ K-PBS buffer solution containing $1 \mathrm{mM} \mathrm{H}_{2} \mathrm{O}_{2}$ for the catalase-immobilized electrode or $1 \mathrm{mM}$ catechol for the tyrosinase-immobilized electrode at $\mathrm{pH}$ 7.0. One milliliter of buffer solution was added into the measuring cell. After achieving a steady background current, the measurement was started by adding $1-200 \mathrm{mM}$ of a standard azide solution $(0.1$ $10 \mu \mathrm{l})$ into the buffer solution contained in the measuring cell, and the current difference (nA) between the stationary currents was recorded for plotting a calibration curve. A syringe was used between each measurement for sucking the buffer solution out of the measuring cell to remove the azide.

\section{Results and Discussion}

A bare screen-printed electrode showed no current response to azide, but a high current response of $3480 \mathrm{nA}$ to $1 \mathrm{mM} \mathrm{H}_{2} \mathrm{O}_{2}$. The catalase-immobilized screen-printed electrode exhibited no apparent current response to $1 \mathrm{mM} \mathrm{H} \mathrm{H}_{2}$ due to the enzymatic decomposition of $\mathrm{H}_{2} \mathrm{O}_{2}$ by catalase. Figure 2(A) shows a current-time curve with the catalase-immobilized electrode obtained by adding various amounts of azide. As shown in the figure, after the injection of azide, the anodic current increased due to a decrease of $\mathrm{H}_{2} \mathrm{O}_{2}$ consumption by catalase, and the increase of the anodic current was proportional to the concentration of azide. The response of the sensor was rapid (1 s) with a high reproducibility and a short recovery time (1 min). The steady background current increased after the addition of azide and reached a new steady state within $30 \mathrm{~s}$. Therefore, the total measurement using the sensor took less than $3 \mathrm{~min}$. Figure 2(B) shows a calibration curve for azide with the catalaseimmobilized electrode. A linear relationship was obtained between the current response and the concentration of azide from $0.1 \mu \mathrm{M}$ to $50 \mu \mathrm{M}$ with a slope of $18.51 \mathrm{nA} \mu \mathrm{M}^{-1}$ and a correlation coefficient of 0.9923 . This method also has a high reproducibility with a RSD of $6.6 \%$ for 5 different catalase-
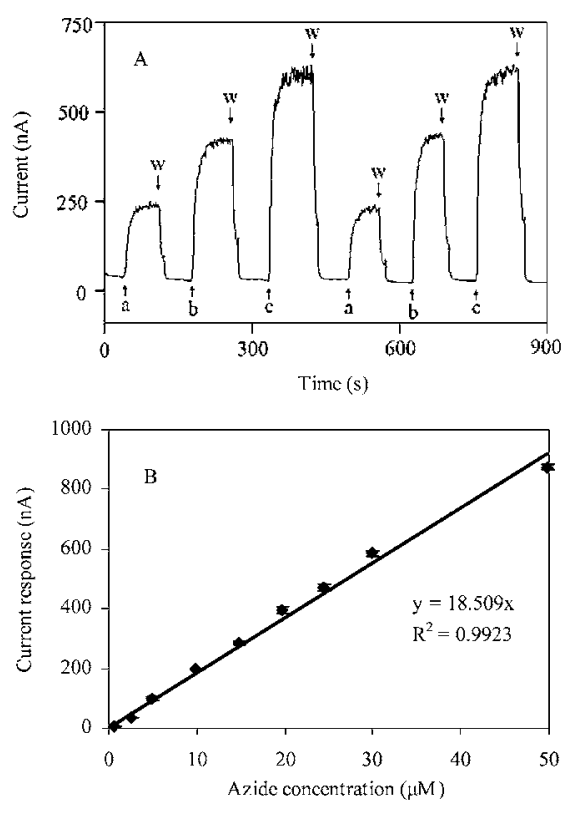

Fig. 2 Determination performance with the catalase-immobilized electrode. (A) Current-time curve to (a) 10 , (b) 20 , (c) $30 \mu \mathrm{M}$ of azide with (w) washing step. (B) Calibration curve for azide $(n=3)$ (sensor, $75 \mathrm{U}$ catalase with $1 \%$ glutaraldehyde in $0.5 \mu \mathrm{l}$ of enzyme matrix; buffer, $50 \mathrm{mM} \mathrm{K}$-PBS buffer containing $1 \mathrm{mM} \mathrm{H}_{2} \mathrm{O}_{2}$ at $\mathrm{pH}$ 7.0).

immobilized electrodes by testing the sensitivity. Compared to the biosensor methods reported previously, ${ }^{10-12}$ this method shows high-performance characteristics with a most sensitive detection range, a short measuring time and an easy-to-handle operation.

A bare screen-printed electrode showed a high current response of $2350 \mathrm{nA}$ to $1 \mathrm{mM}$ catechol, and the tyrosinaseimmobilized screen-printed electrode exhibited a current response of $350 \mathrm{nA}$ to $1 \mathrm{mM}$ catechol due to incomplete consumption of catechol by tyrosinase. Figure 3(A) shows a current-time curve with the tyrosinase-immobilized electrode obtained by adding various amounts of azide. As shown in the figure, after the injection of azide, the anodic current increased due to a decrease of catechol consumption by tyrosinase; the increase of the anodic current was proportional to the concentration of azide. The response of the sensor was rapid (1 s) with a high reproducibility and a short recovery time (1 min). The steady background current increased after the addition of azide, and reached a new steady state within $30 \mathrm{~s}$. Therefore, the total measurement using the sensor took less than $3 \mathrm{~min}$. Figure 3(B) shows the calibration curve for azide with the tyrosinase-immobilized electrode. A linear relationship was obtained between the current response and the concentration of

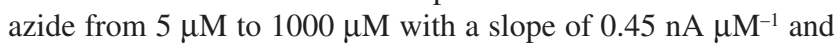
a correlation coefficient of 0.9989 . This method also has a high reproducibility with a RSD of $4.5 \%$ for 5 different tyrosinaseimmobilized electrodes by testing the sensitivity. Under this experimental condition, the determination of azide using the tyrosinase-immobilized electrode was not as sensitive as that using a catalase-immobilized electrode, which was probably due to the inhibition effect of azide on tyrosinase being not as large as that on catalase.

In summary, we demonstrated the amperometric measurements of azide based on its inhibition of enzymatic consumption of hydrogen peroxide or catechol using a disposable, screen- 

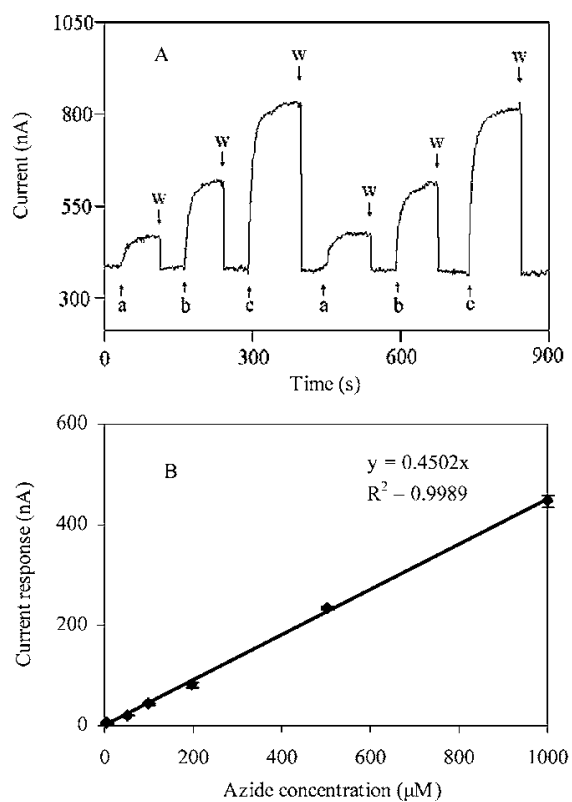

Fig. 3 Determination performance with the tyrosinase-immobilized electrode. (A) Current-time curve to (a) 200, (b) 500, (c) $1000 \mu \mathrm{M}$ of azide with (w) washing step. (B) Calibration curve for azide $(n=3)$ (sensor, $75 \mathrm{U}$ tyrosinase with $1 \%$ glutaraldehyde in $0.5 \mu \mathrm{l}$ of enzyme matrix; buffer, $50 \mathrm{mM} \mathrm{K-PBS}$ buffer containing $1 \mathrm{mM}$ catechol at $\mathrm{pH}$ 7.0).

printed electrode immobilized with catalase or tyrosinase Either of these methods provides a new analytical approach to the determination of azide that is rapid, sensitive, economical and easy-to-handle. Besides, the two methods also provide new analytical methods for the determinations of some other toxic substances.

\section{Acknowledgements}

The authors gratefully acknowledge Hong Kong Research Grant Council (HKUST6253-02P and 510-0091-02-44000-0) for the financial support.

\section{References}

1. E. A. Betterton, Crit. Rev. Env. Sci. Tec., 2003, 33, 423.

2. W. H. Heeschen, E. H. Ubben, P. Gyodi, and P. Beer, Kieler. Milchw. Forsch., 1993, 45, 109.

3. J. P. Hagenbuch, Chimia, 2003, 57, 773 .

4. S. J. Chang and S. H. Lamm, Int. J. Toxicol., 2003, 22, 175.

5. P. L. Annable and L. A. Sly, J. Chromatogr., 1991, 546, 325.

6. R. Kruszyna, R. P. Smith, and H. Kruszyna, J. Forensic. Sci., 1998, 43, 200.

7. S. Kage, K. Kudo, and N. Ikeda, J. Anal. Toxicol., 2000, 24, 429.

8. J. Vacha, M. Tkaczykova, and M. Rejholcova, J. Chromatogr. A, 1989, 488, 506.

9. K. Tsuge, M. Kataoka, and Y. Seto, J. Anal. Toxicol., 2001, 25,228

10. D. Leech and F. Daigle, Analyst, 1998, 123, 1971.

11. F. Daigle, F. Trudeau, G. Robinson, M. R. Smyth, and D. Leech, Biosens. Bioelectron., 1998, 13, 417.

12. M. K. Sezginturk, T. Goktug, and E. Dinckaya, Biosens. Bioelectron., 2005, 21, 684. 